\section{(6) OPEN ACCESS}

\title{
Low-dose prednisone chronotherapy for rheumatoid arthritis: a randomised clinical trial (CAPRA-2)
}

\author{
Frank Buttgereit, ${ }^{1}$ Daksha Mehta, ${ }^{2}$ John Kirwan, ${ }^{3}$ Jacek Szechinski, ${ }^{4}$ Maarten Boers, ${ }^{5}$ \\ Rieke E Alten, ${ }^{6}$ Jerzy Supronik, ${ }^{7}$ Istvan Szombati, ${ }^{8}$ Ulrike Romer, ${ }^{9}$ Stephan Witte, ${ }^{9}$ \\ Kenneth G Saag ${ }^{10}$
}

\begin{abstract}
- Additional material is published online only. To view these files please visit the journal online (http://ard.bmi.com/ content/early/recent)

'Department of Rheumatology and Clinical Immunology, Charité University Medicine, Berlin, Germany

${ }^{2}$ Center for Arthritis and Osteoporosis, Elizabethtown, Kentucky, USA

${ }^{3}$ University of Bristol, Bristol, UK ${ }^{4}$ Katedra I Klinika Reumatologii I Chorob Wewnetrznych AM, Wroclaw, Poland

${ }^{5}$ VU University Medical Center, Amsterdam, Netherlands ${ }^{6}$ Department of Internal Medicine, Rheumatology, Schlosspark-Klinik, Charité Teaching Hospital, Berlin, Germany

${ }^{7}$ NZOZ Centrum Medyczne, Bialystok, Poland ${ }^{8} \mathrm{OEC}$, Budapest, Hungary ${ }^{9}$ Horizon Pharma GmbH, Mannheim, Germany

${ }^{10}$ Division of Clinical Immunology and Rheumatology, University of Alabama at Birmingham, Birmingham, Alabama, USA
\end{abstract}

\section{Correspondence to} Frank Buttgereit, Department of Rheumatology and Clinical Immunology, Charité University Medicine, Berlin 10117, Germany; frank.buttgereit@charite.de

Accepted 25 March 2012

Published Online First

5 May 2012

\section{ABSTRACT}

Objective To assess the efficacy and safety of low-dose prednisone chronotherapy using a new modified-release (MR) formulation for the treatment of rheumatoid arthritis (RA).

Methods In this 12-week, double-blind, placebocontrolled study, patients with active RA $(n=350)$ were randomised 2:1 to receive MR prednisone $5 \mathrm{mg}$ or placebo once daily in the evening in addition to their existing RA disease-modifying antirheumatic drug (DMARD) treatment. The primary end point was the percentage of patients achieving a $20 \%$ improvement in RA signs and symptoms according to American College of Rheumatology criteria (ie, an ACR20 response) at week 12. Changes in morning pain, duration of morning stiffness, 28-joint Disease Activity Score and healthrelated quality of life were also assessed.

Results MR prednisone plus DMARD treatment produced higher response rates for ACR20 (48\% vs $29 \%, p<0.001)$ and ACR50 (22\% vs 10\%, p<0.006) and a greater median relative reduction from baseline in morning stiffness (55\% vs 35\%, $p<0.002)$ at week 12 than placebo plus DMARD treatment. Significantly greater reductions in severity of RA (Disease Activity Score 28) $(p<0.001)$ and fatigue (Functional Assessment of Chronic Illness Therapy-Fatigue score) ( $p=0.003)$ as well as a greater improvement in physical function (36-item ShortForm Health Survey score) $(p<0.001)$ were seen at week 12 for MR prednisone versus placebo. The incidence of adverse events was similar for MR prednisone (43\%) and placebo (49\%).

Conclusion Low-dose MR prednisone added to existing DMARD treatment produced rapid and relevant improvements in RA signs and symptoms.

ClinicalTrials.gov, number NCT00650078

\section{INTRODUCTION}

Glucocorticoids such as prednisone are established components of treatment strategies for many inflammatory conditions, such as rheumatoid arthritis (RA), and are widely used. ${ }^{1-3}$ Accumulating evidence suggests that low-dose treatment is well tolerated and minimises the risk of the undesirable effects associated with higher doses. ${ }^{4}$ However, there is still a need to improve the risk-benefit profile for these valuable anti-inflammatory drugs by increasing the efficacy of low-dose treatment. One promising approach is chronotherapy, in which the delivery of treatment is coordinated with circadian biological rhythms. The chronotherapeutic approach has shown promise in several therapeutic areas, including the management of hypertension, allergic rhinitis and bronchial asthma. $^{5-7}$

Chronotherapy may be particularly appropriate for RA because symptoms follow circadian rhythms, with impaired function due to pain and joint stiffness commonly being most severe in the early morning. ${ }^{89}$ Emergence of these symptoms follows the increase in serum levels of interleukin 6 (IL-6; a key inflammatory mediator), tumour necrosis factor $\alpha$ (TNF $\alpha)$ and other proinflammatory cytokines that occur late at night. ${ }^{9-13}$ Nocturnal secretion of cortisol, which can counter the effects of increased IL-6 levels, is also perturbed in patients with RA and may contribute to the emergence of morning symptoms. ${ }^{814}$ These observations suggest that the optimal time for delivery of glucocorticoid treatment is during the night, to mimic the normal circadian rhythm of cortisol secretion and target the effects of nocturnal proinflammatory stimuli.

A modified-release (MR) formulation of prednisone has been developed to deliver prednisone chronotherapy. This innovative tablet uses a programmed-release mechanism to release prednisone approximately $4 \mathrm{~h}$ after ingestion (ie, at approximately 02:00 am if the patient takes the tablet at 10:00 pm). We report the results of a double-blind, placebo-controlled, multicentre study (Circadian Administration of Prednisone in Rheumatoid Arthritis, CAPRA-2) that investigated the efficacy and safety of low-dose prednisone chronotherapy in patients with active RA.

This is the first rigorous placebo-controlled study to investigate the efficacy of low-dose prednisone in patients with active disease receiving disease-modifying antirheumatic drug (DMARD) treatment and according to current standards. It thus allows comparison with the results of recent studies of other treatments in patients with active RA.

\section{METHODS}

Study design

In this 12-week, double-blind, parallel-group, placebo-controlled study, following a 1-week screening period, eligible patients were randomised 2:1 to receive MR prednisone (5 mg) or placebo once daily, taken with or after their evening meal, in addition to their standard RA treatment. 
The study was conducted in accordance with the International Conference on Harmonisation Guidelines for Good Clinical Practice and the Declaration of Helsinki. The protocol was approved by the ethics committees and institutional review boards of all centres, and all patients provided written informed consent before study-related procedures. The trial is registered at ClinicalTrials.gov, number NCT00650078.

\section{Patients}

Patients aged 18-80 years with a diagnosis and documented history of RA and who had been taking DMARDs for at least 6 months were eligible for inclusion. Patients were also required to have had a duration of morning stiffness of at least $45 \mathrm{~min}$ on at least 4 days within the 7 days of screening, a swollen joint count of $\geq 4$ and a tender joint count of $\geq 4$. Patients receiving oral glucocorticoids within 6 weeks of the screening visit were excluded from the study (see online supplementary material for further details). The study protocol prohibited initiation of any new DMARD or non-steroidal anti-inflammatory drug (NSAID) treatment during the study; changes to existing DMARD treatment (dosing and frequency) were also prohibited.

\section{Outcomes and follow-up}

Scheduled study visits occurred at baseline and weeks 2, 6 and 12 , and were to occur between 08:00 and 10:00 pm. At each visit, doctors assessed the number of tender and swollen joints and global disease activity, and patients assessed pain and global disease activity and completed the Functional Disability Index of the Health Assessment Questionnaire. ${ }^{15}$ Disease activity at each visit was determined using the 28-joint Disease Activity Score (DAS28). ${ }^{16}$ Assessments of pain and global disease activity were made using $0-100 \mathrm{~mm}$ visual analogue scales $(0=$ no pain/ not active at all; $100=$ very intense pain/extremely active). Blood samples were collected at each study visit.

Throughout the study, patients completed a diary card twice daily. In the mornings they recorded whether they had joint stiffness and its severity, the time of resolution of joint stiffness and pain levels on waking. Evening assessments included pain intensity during the day and whether the patient had experienced recurrence of stiffness. Patients assessed their health status using the 36-item Short-Form Health Survey (SF-36), ${ }^{17} 18$ and the Functional Assessment of Chronic Illness TherapyFatigue (FACIT-F) questionnaire ${ }^{1920}$ at baseline and week 12 . Safety assessments (recording of adverse events (AEs) and vital signs) were performed at each study visit according to standard procedure (ie, without using checklists with predefined events).

The primary efficacy end point was the proportion of patients with a $20 \%$ improvement in RA signs and symptoms according to American College of Rheumatology (ACR) criteria (ie, an ACR20 response) $)^{21}$ at week 12 . A key secondary end point was the change in duration of morning stiffness between baseline and week 12. (See online supplementary material for details of secondary end points.)

\section{Statistical analysis}

The study aimed to demonstrate a difference of at least $20 \%$ in ACR20 for MR prednisone versus placebo at week 12. The sample size calculation was based on comparison of two proportions using the $\chi^{2}$ test and a randomisation ratio of $2: 1$ for MR prednisone:placebo. Assuming an ACR20 response rate of $25 \%$ for placebo, 294 patients would be required to provide $90 \%$ power to detect an ACR2 0 response rate of $45 \%$ in the MR prednisone group at a significance level of $\alpha=0.05$. The study therefore aimed to randomise at least 294 patients; in order to account for potential drop-outs, a total of 350 patients were recruited to the study.

Duration of morning stiffness was the difference between the time of resolution of morning stiffness and the time of waking. The difference between the treatment groups was assessed using the median and the $95 \%$ CI of the median, computed using the Hodges-Lehmann method. (See supplementary material for further details.)

\section{RESULTS}

\section{Study population}

A total of 350 patients were randomised between April 2008 and February 2009; of these, 323 (92.3\%) completed the study (figure 1 and supplementary table 1 ). The main reasons for early withdrawal were AEs and patient requests. Demographics and baseline disease characteristics were generally well balanced between the two treatment groups (table 1). The study population was primarily female ( $84 \%$ ), aged $>45$ to $<65$ years $(70 \%)$, and about half of the study population (55\%) had had RA for at least 5 years. All patients had previously received treatment for RA: $99 \%$ with DMARDs and 73\% with NSAIDs.

Virtually all patients (>98\%) received concomitant DMARD treatment, the most frequently used being methotrexate $(73.7 \%$ of patients), sulfasalazine (14.6\%) and leflunomide (11.1\%). Analgesic use was similar between treatment groups (MR prednisone, $83.1 \%$; placebo, $86.6 \%$ ). The most frequently used analgesics were anilides (27.4\% of patients), acetic acid derivatives $(25.1 \%)$ and propionic acid derivatives (17.1\%). Detailed analysis showed no significant changes in DMARD and NSAID use between baseline and end of study (supplementary table 2) indicating that observed results were not confounded by changes in concomitant treatment.

\section{Efficacy}

\section{ACR response rate}

ACR20 and ACR50 response rates at week 12 were significantly greater with $\mathrm{MR}$ prednisone than with placebo. At week 12, $48 \%$ of patients receiving MR prednisone achieved an ACR20 response, compared with $29 \%$ in the placebo group, a difference of $19 \%(p<0.001)$. The response was achieved rapidly: a significant difference in ACR20 response rate between treatment groups was evident at week 2 , and the difference remained significant throughout the study $(\mathrm{p}<0.005)$ (figure $2 \mathrm{~A})$.

ACR50 responder rates were numerically greater with $M R$ prednisone than with placebo at all time points, and the difference was significant at weeks 6 and $12(22 \%$ vs $10 \%$ at week $12, \mathrm{p}<0.006)$. Few patients had an ACR70 response at week 12: $7 \%$ of those taking $M R$ prednisone and $3 \%$ of placebo recipients $(\mathrm{p}=0.10)$.

\section{Individual ACR core set measures}

All individual ACR core set measures except C-reactive protein and erythrocyte sedimentation rate showed significantly greater improvements from baseline to week 12 with MR prednisone than with placebo (table 2). Changes from baseline were also significantly different between the placebo and $M R$ prednisone groups at weeks 2 and 6 for all clinical end points $(p<0.05)$.

\section{Patients achieving low disease activity}

MR prednisone significantly increased the proportion of patients achieving low disease activity (defined as having a 28-joint Disease Activity Score (DAS28) $\leq 3.2)$ after 6 weeks $(p<0.001)$ and 12 weeks $(p=0.0109)$ of treatment (supplementary table 3 ). 


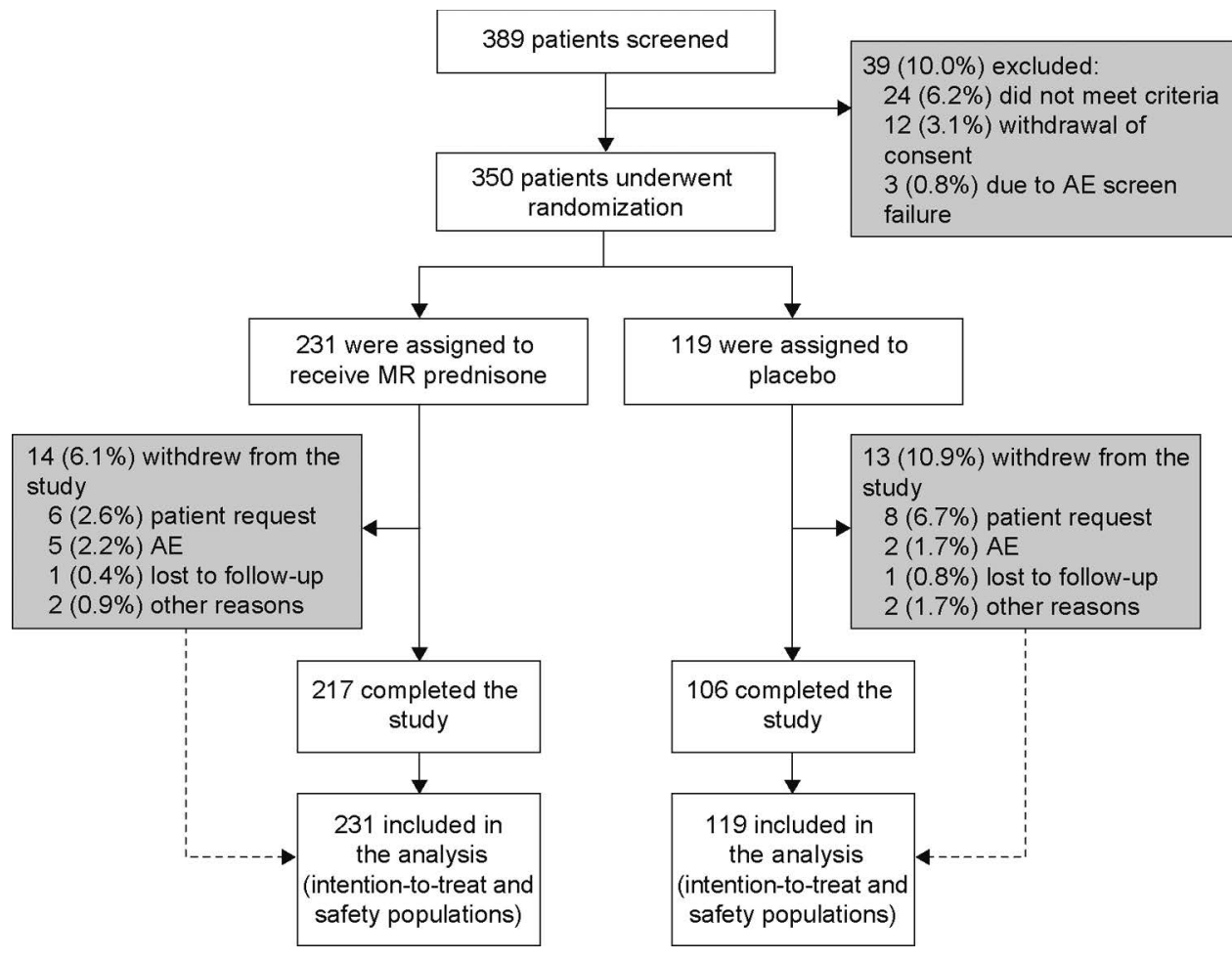

Figure 1 Patient disposition. A total of 350 patients were enrolled from 50 centres in six countries: Germany ( 3 centres, 3 patients), UK ( 3 centres, 12 patients), Poland (10 centres, 145 patients), Hungary ( 9 centres, 102 patients), Canada ( 2 centres, 13 patients) and USA (23 centres, 75 patients). $\mathrm{AE}$, adverse event; $\mathrm{MR}$, modified release.

At 12 weeks, $11.3 \%$ patients in the MR prednisone group had achieved a DAS28 score $<2.6$ (disease remission or, according to Felson et al, ${ }^{22}$ minimal disease activity) compared with $6.7 \%$ in the placebo group.

\section{Morning stiffness}

At baseline, the median duration of morning stiffness was similar between the two treatment groups: MR prednisone, $127 \mathrm{~min}$; placebo, $139 \mathrm{~min}$. At week 12, the median duration of morning stiffness was $46 \mathrm{~min}$ in the MR prednisone group (median relative reduction from baseline of 55\%), compared with 79 min for placebo (median relative reduction from baseline of $35 \%$ ). The difference between groups in median relative reduction in duration of morning stiffness was significant at weeks 2, 6 and 12 ( $p<0.004$ for all comparisons) (figure 2B). Significantly greater decreases in the severity of morning stiffness and recurrence of stiffness later in the day were also seen for MR prednisone compared with placebo $(\mathrm{p} \leq 0.01)$ (table 2). Further analysis showed no correlation between disease duration and effect on morning stiffness (supplementary table 4) and a regression analysis showed that duration of RA was not a predictor of reduced duration of morning stiffness ( $\mathrm{p}=0.8433$ ).

\section{Morning and evening pain}

At baseline, both groups reported having considerable morning pain (table 1). Reductions in morning pain from baseline were seen in both treatment groups and were significantly greater in the MR prednisone group at all time points $(\mathrm{p} \leq 0.05)$ (table 2$)$. Significantly greater reductions in evening pain from baseline were also seen for the MR prednisone group $(p<0.05)$ (table 2$)$.

Health-related quality of life

At baseline, patients were experiencing considerable fatigue compared with the general population, as indicated by mean
FACIT-F scores (MR prednisone, 29; placebo, 29; general population, 44). ${ }^{19}$ FACIT-F scores increased in both treatment groups over the course of the study, indicating a reduction in fatigue; the change was significantly greater in the MR prednisone group $(\mathrm{p}=0.003)$ (table 2).

Improvements in physical function and mental function were also observed over the course of the study in both treatment groups, according to SF-36 assessments (table 2). At baseline, mean scores for physical function (MR prednisone, 32; placebo, 31) were well below that of the US general population - namely, $50 .{ }^{18}$ The improvement in physical function was significantly greater in the MR prednisone group (3.6 vs 1.3, $\mathrm{p}<0.001$ ).

\section{Laboratory variables}

IL-6 levels at screening were highly variable (table 1), and more than $50 \%$ of patients had levels below the limit of detection. Over the 12-week study, IL-6 levels decreased in both treatment groups. The decrease in IL- 6 was greater in the MR prednisone group as evident from the geometric mean titre ratio of 0.8 (95\% CI 0.7 to 0.9 ). Minor increases in C-reactive protein levels and decreases in erythrocyte sedimentation rate were seen over the course of the study and were similar in the two treatment groups (table 2). TNF $\alpha$ levels in the two groups were comparable at baseline (table 1) and levels remained unchanged over the 12-week study; the geometric mean titre ratio was 1.0 ( $95 \%$ CI 0.97 to 1.04) for the change in TNFo levels between treatments.

\section{Safety and tolerability}

MR prednisone was generally well tolerated, and there were no deaths or life-threatening AEs. The incidence of AEs was slightly lower in the MR prednisone group than the placebo group (43\% vs $49 \%)$. The incidence of AEs regarded by investigators as 
Table 1 Demographics and baseline disease characteristics

\begin{tabular}{|c|c|c|}
\hline Characteristics & $\begin{array}{l}\text { MR prednisone } \\
(\mathrm{n}=231)\end{array}$ & $\begin{array}{l}\text { Placebo } \\
(n=119)\end{array}$ \\
\hline \multicolumn{3}{|l|}{ Demographic and disease characteristics } \\
\hline \multicolumn{3}{|l|}{ Age, years } \\
\hline Mean $\pm S D$ & $57.1 \pm 9.9$ & $57.5 \pm 9.6$ \\
\hline Median (range) & $57.0(27-80)$ & $58.0(32-76)$ \\
\hline Female sex, $\mathrm{n}(\%)$ & $192(83.1)$ & $102(85.7)$ \\
\hline White race, $\mathrm{n}(\%)$ & $226(97.8)$ & $118(99.2)$ \\
\hline $\mathrm{BMI}$, mean $\pm \mathrm{SD}, \mathrm{kg} / \mathrm{m}^{2}$ & $28.0 \pm 5.8$ & $28.1 \pm 5.5$ \\
\hline \multicolumn{3}{|l|}{ Duration of RA } \\
\hline Mean (years) & 7.98 & 7.94 \\
\hline$<2$ Years, n (\%) & $41(17.7)$ & $29(24.4)$ \\
\hline \multicolumn{3}{|l|}{ Previous RA treatments, $\mathrm{n}(\%)$} \\
\hline DMARDs & $228(98.7)^{*}$ & $119(100)$ \\
\hline NSAIDs & $166(71.9)$ & 88 (73.9) \\
\hline Other analgesics & $84(36.4)$ & $53(44.5)$ \\
\hline Biological treatments & $1(0.4)$ & $1(0.8)$ \\
\hline \multicolumn{3}{|c|}{ ACR core set measures, mean \pm SD (unless stated) } \\
\hline Tender joint count & $12.6 \pm 6.17$ & $12.5 \pm 5.94$ \\
\hline Swollen joint count & $8.4 \pm 4.40$ & $8.6 \pm 4.65$ \\
\hline Patient assessment of pain†‡ & $58(3-96)$ & $51(0-95)$ \\
\hline Patient assessment of disease activity $\dagger$ & $57.4 \pm 20.1$ & $50.9 \pm 20.9$ \\
\hline Physician assessment of disease activity ${ }^{\prime}$ & $55.2 \pm 16.1$ & $54.1 \pm 17.4$ \\
\hline HAQ-DI score & $1.3 \pm 0.6$ & $1.3 \pm 0.6$ \\
\hline $\mathrm{CRP}, \mathrm{mg} / \mathrm{l}$ & $5.2(<0.05-91.5)$ & $5.3(0.1-136.5)$ \\
\hline $\mathrm{ESR}, \mathrm{mm} / \mathrm{h} \ddagger$ & $32(4-104)$ & $30(2-115)$ \\
\hline \multicolumn{3}{|l|}{ Other clinical end points, mean $\pm S D$} \\
\hline Duration of morning stiffness, min & $152.0 \pm 92.4$ & $156.7 \pm 87.7$ \\
\hline Severity of morning stiffness $\dagger$ & $54.6 \pm 21.7$ & $50.7 \pm 21.3$ \\
\hline Recurrence of stiffness, $\%$ of days & $68.3 \pm 39.0$ & $72.1 \pm 37.3$ \\
\hline Morning pain score $\dagger$ & $54.9 \pm 21.6$ & $50.5 \pm 22.4$ \\
\hline Evening pain score† & $49.9 \pm 23.5$ & $47.8 \pm 21.9$ \\
\hline DAS28 & $5.2 \pm 0.8$ & $5.1 \pm 0.8$ \\
\hline \multicolumn{3}{|l|}{ Health-related quality of life, mean \pm SD } \\
\hline FACIT-F score & $28.8 \pm 10.4$ & $28.7 \pm 10.7$ \\
\hline SF-36 physical components summary score & $31.6 \pm 7.0 \S$ & $31.5 \pm 6.9$ \\
\hline SF-36 mental components summary score & $45.3 \pm 10.7 \S$ & $45.4 \pm 9.6$ \\
\hline $\begin{array}{l}\text { Inflammatory markers, median (range) } \\
\text { IL-6, pg/ml }\end{array}$ & $<5(<5-3215) \uparrow$ & $<5(<5-266)$ \\
\hline $\mathrm{TNF} \alpha, \mathrm{pg} / \mathrm{ml}$ & $<5(<5-65) \uparrow$ & $<5(<5-15)$ \\
\hline
\end{tabular}

${ }^{*}$ Three patients in the MR prednisone group did not take DMARDs during the study, but they were not uncovered until unblinding.

†Values in mm, measured using a $0-100$ visual analogue scale.

咆a presented as median (range).

$\S$ Data missing for two patients.

IData missing for one patient.

BMI, body mass index; CRP, C-reactive protein; DAS28, 28-joint Disease Activity Score; DMARD, disease-modifying antirheumatic drug; ESR, erythrocyte sedimentation rate;

FACIT-F, Functional Assessment of Chronic Illness Therapy-Fatigue; HAQ-DI, Functional Disability Index of the Health Assessment Questionnaire; IL-6, interleukin 6; MR,

modified release; NSAID, non-steroidal anti-inflammatory drug; RA, rheumatoid arthritis; SF-36, 36-item Short-Form Health Survey; TNF, tumour necrosis factor.

being related to treatment was similar in the two groups $(7.8 \%$ vs $8.4 \%$ ) (table 3 ). In both treatment groups, the most frequently occurring AEs were related to worsening of the underlying disease-namely, arthralgia and aggravated RA/RA flare-up, and these occurred more frequently in the placebo group. The difference in incidence was statistically significant for arthralgia $(\mathrm{p}=0.0141)$, but not for aggravated RA/RA flare-up ( $\mathrm{p}=0.3917)$. The incidence of infections was similar for the two groups (MR prednisone, $13 \%$; placebo, $12 \%$ ), as was the incidence of the most frequently reported infection, nasopharyngitis; bronchitis was reported more frequently for the placebo group, though the increase was not significant (table 3). Most events were mild or moderately severe.

Serious AEs were reported for one patient $(0.4 \%)$ receiving MR prednisone and two (1.7\%) receiving placebo (table 3 ); none
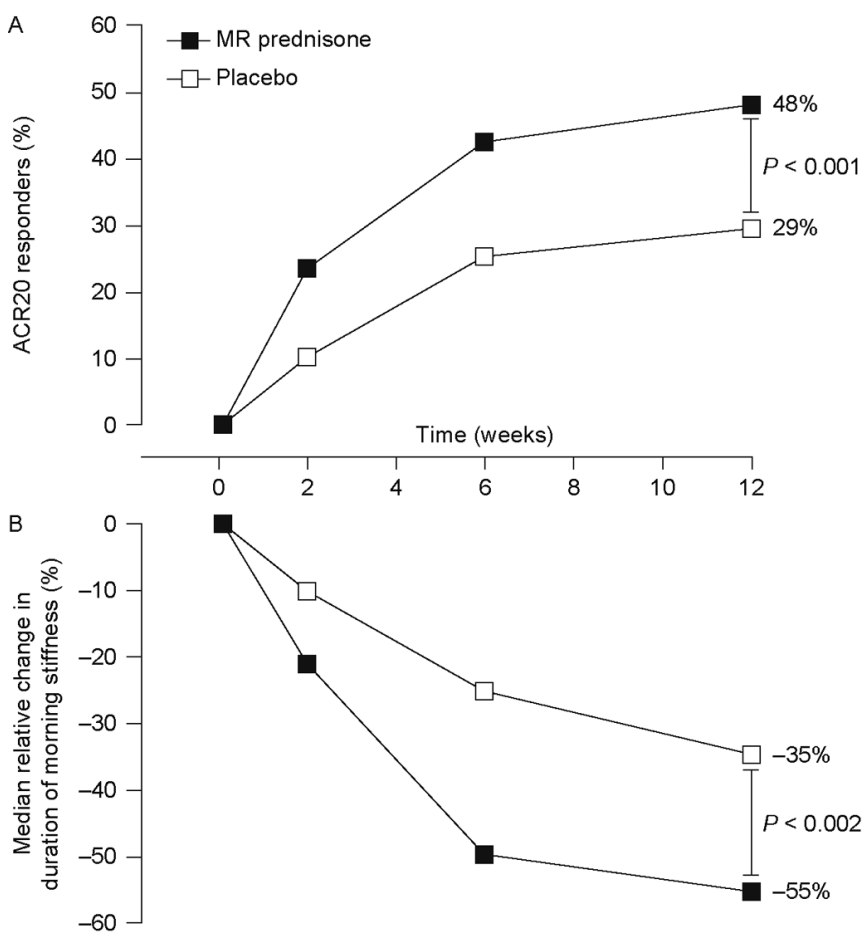

Figure 2 Improvements in rheumatoid arthritis symptoms. (A) Percentage of patients achieving a $20 \%$ improvement in rheumatoid arthritis signs and symptoms according to American College of Rheumatology criteria (ACR20) (primary end point). $p<0.003$ for the between-group difference at weeks 2, 6 and 12. (n Values for weeks 2, 6 and 12 were 231, 229 and 229, respectively, for the modifiedrelease (MR) prednisone group and 119, 119 and 119, respectively, for the placebo group.) (B) Change in duration of morning stiffness from baseline. $p<0.004$ for the between-group difference at weeks 2, 6 and 12. (n Values for weeks 2, 6 and 12 were 228, 220 and 216, respectively, for the MR prednisone group and 119, 112 and 107 for the placebo group.)

of the serious AEs were considered severe or related to study treatment. Six patients withdrew from the study because of AEs, five $(2.2 \%)$ in the MR prednisone group (due in one case each to: headache, headache and hypertension, glaucoma, RA flare and vomiting) and one (0.8\%) in the placebo group (due to headache); all events except the case of RA flare in the MR prednisone group were considered related to treatment. No clinically relevant changes in haematological or biochemical parameters or vital signs were seen during the study.

\section{DISCUSSION}

Low-dose MR prednisone chronotherapy has an important clinical effect on symptoms of RA in patients with active disease receiving conventional DMARDs, as evident from ACR20 and ACR50 response rates at week 12 in this study. Clinical responses were achieved rapidly, with most clinical end points showing statistically significant differences for MR prednisone over placebo as early as 2 weeks after the start of treatment, and responses were maintained for the duration of the 12 -week study. Significant improvements in health-related quality of life (HRQoL) were also seen. The use of analgesics was similar between groups, indicating that the observed improvements could be attributed to MR prednisone, rather than differences in analgesic medication. 
Table 2 Mean change from baseline at week 12 in clinical variables and health-related quality-of-life end points* ${ }^{*}$

\begin{tabular}{|c|c|c|c|c|}
\hline & \multicolumn{2}{|c|}{ LSM Change from baseline } & \multirow[b]{2}{*}{$\begin{array}{l}\text { LSM } \\
\text { Difference } \pm \text { SE }\end{array}$} & \multirow[b]{2}{*}{$\mathrm{p}_{\text {Valuef }}$} \\
\hline & $\begin{array}{l}\text { MR } \\
\text { Prednisone }\end{array}$ & Placebo & & \\
\hline \multicolumn{5}{|l|}{ ACR core set measures } \\
\hline Tender joint count & -4.7 & -2.7 & $-2.0 \pm 0.6$ & 0.001 \\
\hline Swollen joint count & -3.3 & -2.2 & $-1.1 \pm 0.4$ & 0.009 \\
\hline Patient pain scoreł & -21.0 & -12.7 & $-8.3 \pm 2.5$ & 0.001 \\
\hline Patient global scoreł & -17.3 & -7.9 & $-9.3 \pm 2.5$ & $<0.001$ \\
\hline Physician global scoreł & -22.8 & -13.1 & $-9.6 \pm 2.2$ & $<0.001$ \\
\hline HAQ-DI score & -0.238 & -0.079 & $-0.16 \pm 0.04$ & $<0.001$ \\
\hline $\mathrm{CRP}, \mathrm{mg} / \mathrm{l}$ & 0.86 & 0.88 & $0.98 \S$ & 0.86 \\
\hline $\begin{array}{l}\text { ESR after } 1 \mathrm{~h}, \mathrm{~mm} / \mathrm{h} \\
\text { Other clinical end points }\end{array}$ & -7.3 & -5.9 & $-1.4 \pm 1.5$ & 0.34 \\
\hline $\begin{array}{l}\text { Severity of morning } \\
\text { stiffness } \ddagger\end{array}$ & -27.4 & -19.6 & $-7.8 \pm 2.8$ & 0.007 \\
\hline $\begin{array}{l}\text { Recurrence of stiffness, } \\
\% \text { of days (mean) }\end{array}$ & -20.3 & -6.7 & $-13.6 \pm 4.5$ & 0.003 \\
\hline Morning pain scoreł & -23.1 & -16.4 & $-6.7 \pm 2.6$ & 0.012 \\
\hline Evening pain scoreł & -20.2 & -14.9 & $-5.3 \pm 2.7$ & 0.049 \\
\hline DAS28 score & -1.15 & -0.63 & $-0.52 \pm 0.13$ & $<0.001$ \\
\hline \multicolumn{5}{|c|}{ Health-related quality of life } \\
\hline FACIT-fatigue score & 3.8 & 1.6 & $2.2 \pm 0.8$ & 0.003 \\
\hline $\begin{array}{l}\text { SF-36 physical component } \\
\text { score }\end{array}$ & 3.6 & 1.3 & $2.3 \pm 0.6$ & $<0.001$ \\
\hline $\begin{array}{l}\text { SF-36 mental component } \\
\text { score }\end{array}$ & 2.0 & 0.9 & $1.1 \pm 0.7$ & 0.14 \\
\hline
\end{tabular}

*Plus-minus values are means \pm SD.

tSee figure 2 for changes in ACR20 response rate and duration of morning stiffness. Changes in interleukin 6 and tumour necrosis factor $\alpha$ from baseline to week 12 are described in the text.

$\ddagger$ Values in mm, measured using a 0-100 visual analogue scale.

$\S$ Geometric mean titre ratio for MR prednisone versus placebo.

ACR, American College of Rheumatology; CRP, C-reactive protein; DAS28, 28-joint

Disease Activity Score; ESR, erythrocyte sedimentation rate; FACIT-F, Functional

Assessment of Chronic Illness Therapy-Fatigue; HAQ-DI, Functional Disability Index of

the Health Assessment Questionnaire; LSM, least-squares mean; MR, modified release;

SF-36, 36-item Short-Form Health Survey.

Prednisone chronotherapy is expected to have a particular impact on morning symptoms of RA. This is borne out in this study, in which MR prednisone reduced the duration of morning stiffness from approximately $2 \mathrm{~h}$ at baseline to $46 \mathrm{~min}$ at week 12 , a median relative reduction of $55 \%$ which was approximately 1.5 -fold greater than that seen with placebo. Morning pain, severity of morning stiffness and RA severity (according to DAS28 score) were also considerably reduced with MR prednisone over the 12 -week study. This is in agreement with results from our previous study (CAPRA-1), ${ }^{23}$ in which MR prednisone induced greater improvements in morning stiffness and reductions in IL-6 levels than immediate-release (IR) prednisone. These results suggest that the timing of delivery significantly affects the efficacy of glucocorticoid treatment and that chronotherapy may allow efficacious treatment with lower glucocorticoid doses.

Previous studies of low-dose prednisone have largely investigated the benefits of adding low-dose ( $\leq 10 \mathrm{mg} /$ day) IR prednisone to DMARDs in patients with early RA. ${ }^{25-30}$ These placebocontrolled studies have demonstrated more rapid improvements in clinical symptoms over the first 6 months of treatment for prednisone compared with placebo, and are thus in agreement with our results obtained in patients with more advanced disease. ${ }^{2528-30}$ While numerical differences in favour of the prednisone group were also evident at 12 or 24 months, differences were no longer statistically significant in most cases. ${ }^{25-28}$ However, the addition of low-dose prednisone has been reported to increase
Table 3 Adverse events

\begin{tabular}{lcc}
\hline Event, $\mathbf{n}(\%)$ & MR prednisone $\mathbf{n = 2 3 1}$ & Placebo $\mathbf{n = 1 1 9}$ \\
\hline Any AE & $99(42.9)$ & $58(48.7)$ \\
Treatment-related AE & $18(7.8)$ & $10(8.4)$ \\
AEs leading to discontinuation* & $5(2.2)$ & $1(0.8)$ \\
Severe AEs ${ }^{*}$ & $3(1.3)$ & $5(4.2)$ \\
Serious AEs $\ddagger$ & $1(0.4)$ & $2(1.7)$ \\
AEs reported in $>1 \%$ of patients & & \\
Arthralgia & $24(10.4)$ & $24(20.2)$ \\
Aggravated RA/RA flare-up & $15(6.5)$ & $11(9.2)$ \\
Nasopharyngitis & $11(4.8)$ & $4(3.4)$ \\
Headache & $9(3.9)$ & $5(4.2)$ \\
Hypertension & $5(2.2)$ & $1(0.8)$ \\
Diarrhoea & $4(1.7)$ & $1(0.8)$ \\
Rash & $4(1.7)$ & $1(0.8)$ \\
Bronchitis & $3(1.3)$ & $5(4.2)$ \\
Back pain & $3(1.3)$ & $1(0.8)$ \\
Vomiting & $3(1.3)$ & $1(0.8)$ \\
Peripheral oedema & $2(0.9)$ & $2(1.7)$ \\
Haematuria & $1(0.4)$ & $3(2.5)$ \\
\hline
\end{tabular}

${ }^{*}$ AEs leading to discontinuation were headache $(n=2)$, glaucoma $(n=1)$, vomiting $(n=1)$, exacerbation of $R A(n=1)$, anxiety $(n=1)$, and hypertension $(n=1)$ for the MR prednisone group, and headache $(n=1)$ for the placebo group. All AEs except exacerbation of RA were considered to be related to treatment.

tSevere AEs were arthropod bite $(n=1)$, joint sprain $(n=1)$ and arthralgia $(n=1)$ in the MR prednisone group, and arthralgia (three events), aggravated RA/RA flare-up (two events) and one event each of headache, gout and epistaxis in the placebo group.

‡The serious $\mathrm{AE}$ in the MR prednisone group was palpitations and chest discomfort. One patient in the placebo group was diagnosed with ischaemic heart disease and another underwent elective uterus extirpation for abnormal cervical cytology. All events were classified as serious because patients required hospitalisation but none was considered related to the study drug.

$A E$, adverse event; MR, modified release; RA, rheumatoid arthritis.

the probability of achieving remission over the first year of treatment and of maintaining remission beyond the first year, ${ }^{30}$ and to decrease radiographic progression. ${ }^{25} 27-29$ Given the similar results reported for IR prednisone and MR prednisone over the first months of treatment, prolonged treatment with MR prednisone can also be expected to slow radiographic progression, but this disease-modifying effect has still to be proved.

We report that MR prednisone was well tolerated. In this 12 -week study, the overall incidence of AEs was slightly lower in patients receiving MR prednisone than in those receiving placebo, and none of the serious or severe AEs in the MR prednisone group was considered related to treatment. In addition, there was no evidence for an increased risk of infection with active treatment; indeed the incidence of bronchitis was higher in the placebo group. The incidences of hypertension and discontinuation due to AEs were low but were slightly higher in the MR prednisone group. Notably, the incidences of arthritis and arthralgia reported as AEs were higher in the placebo group, again reflecting the efficacy of $M R$ prednisone. The safety profile of $M R$ prednisone presented here is similar to that seen in the CAPRA-1 study ${ }^{11}{ }^{23}$ and in placebo-controlled studies for IR prednisone. ${ }^{27} 29$

Our study has several limitations. First, patients were required to have morning stiffness of more than $45 \mathrm{~min}$ to be included in the study; our results may thus not be directly applicable to patients with less severe disease. Second, this was a 12-week study. This duration is sufficient to demonstrate the initial benefits achieved by adding MR prednisone to DMARD treatment, including improvements in morning function and HRQoL. However, the study did not assess effects on structural damage and disease progression, which would require longer follow-up. Third, while the results of this study demonstrate that shortterm treatment with MR prednisone has a similar safety profile 
to that of placebo, long-term studies are required to assess the safety and tolerability of prolonged treatment.

In fact, this has already been demonstrated in the open-label extension to the CAPRA-1 study, where patients received either MR prednisone or IR prednisone for 3 months, before receiving $M R$ prednisone for 9 months. The only AEs reported in $>2 \%$ of patients during the 9-month extension (months 4-12) were RA-related symptoms (14.5\%), upper respiratory tract infections $(2.8 \%)$, back pain $(2.8 \%)$ and weight increase $(2.8 \%) .{ }^{11}$ An integrated safety analysis (supplementary tables 5 and 6) provides further safety data from the full 12 months of CAPRA-1 (either 12 months MR prednisone treatment or 3 months IR prednisone treatment (months $0-3$ ) followed by 9 months MR prednisone treatment (months 4-12) depending on initial randomisation) and combined safety data for patients receiving MR prednisone for 3 months from both CAPRA-1 and CAPRA-2. ${ }^{31}$ The incidence of AEs was higher over the 12 -month period than for the 3 -month period (as would be expected for the longer duration of treatment), though the increase was not proportional to the duration of treatment. For example, the incidence of severe AEs during the first 3 months of treatment was $2.4 \%$ (supplementary table 5) compared with $3.3 \%$ in patients receiving 12 months MR prednisone treatment (supplementary table 6). Similarly, aggravated RA/RA flare-up was reported in $12.8 \%$ of patients during the first 3 months and in $14.2 \%$ of patients during the 12 -month treatment period (supplementary tables 5 and 6). The only AEs reported in $\geq 4 \%$ of patients receiving $M R$ prednisone for 12 months were aggravated RA/RA flare-up and flushing (supplementary table 6).

In conclusion, the results of this study demonstrate that even at a dose considered to be below substitution levels, MR prednisone chronotherapy is highly effective and well tolerated in patients with RA, providing rapid relief of symptoms and, particularly, improving morning function. Further, longer-term studies are warranted to determine the dose and strategy that optimises the benefit-to-risk ratio for $M R$ prednisone in the management of RA.

Acknowledgements The authors thank the patients and investigators who took part in this study. The authors take full responsibility for the content of the paper. They thank Patricia Rice, MS (CliniRx USA) and Sandrine Cayez, MS (ICON Clinical Research SARL) for statistical analysis of the data; Rowena Hughes, PhD and Adam Giles, PhD (Oxford PharmaGenesis ${ }^{\mathrm{TM}}$ ) for medical writing support, editorial assistance and collation and incorporation of comments from all authors; Amy Grahn, MS (Clinical Development and Operations, Horizon Pharma) for thorough data review, and Ivonne Mitar, DPhil (Medical Science Liaison, Horizon Pharma, formerly Nitec Pharma GmbH) for critical review and for coordinating the writing of the manuscript. The editorial help was supported by Horizon Pharma, Mannheim, Germany and Northbrook, IL, USA.

Contributors All authors vouch for the accuracy of data and the analysis, were involved in the decision to publish, and contributed to the interpretation of the data. All authors approved the submitted paper. Medical writing and editorial assistance was provided by Oxford PharmaGenesis. FB had full access to all the data in the study and takes responsibility for the integrity of the data and the accuracy of the analysis. Study design: The study was designed by Horizon Pharma (SW and UR) in conjunction with FB and other coauthors (MB, RA, KGS). Patient recruitment: FB, DM, JK, JSz, RA, JSu, IIS. Data gathering and analysis: Horizon Pharma (Mannheim, Germany). Statistical analysis: Patricia Rice (CliniRx USA, Inc), Sandrine Cayez (ICON Clinical Research SARL).

Funding Horizon Pharma (formerly Nitec Pharma), Mannheim, Germany and Northbrook, Illinois, USA.

Competing interests $\mathrm{FB}$ received consultancy fees, honoraria and travel expenses from Merck Serono, Horizon Pharma (formerly Nitec Pharma) Mundipharma Int Ltd and grant support from Merck Serono and Horizon Pharma. JK received honoraria, consultancy fees, grants and travel expenses paid to his institution from Horizon Pharma (formerly Nitec Pharma), AstraZeneca, CombinatoRx, GlaxoSmithKline, Merck and Wyeth. MB received consultancy fees from Augurex, Bristol-Myers Squibb, CombinatoRx, GlaxoSmithKline, Medimmune, Horizon Pharma (formerly
Nitec Pharma), Mundipharma and Roche; honoraria from Genentech, Novartis and Sanofi; and payment for development of educational presentations from Schering-Plough and UCB. REA received consultancy fees and honoraria from Merck Serono and Horizon Pharma (formerly Nitec Pharma) and travel expenses and payment for development of educational presentations from Merck Serono. KGS received consultancy fees, honoraria and travel expenses from Merck Serono, Horizon Pharma (formerly Nitec Pharma), Novartis, Roche, Amgen, UCB, Genentech and Eli Lilly, and grant support from Merck Serono, Proctor \& Gamble, Roche, GlaxoSmithKline, Amgen and Eli Lilly. SW and UR are employees of Horizon Pharma and have stock options. DM, JSz, JSu and IS reported no conflicts of interest.

Provenance and peer review Not commissioned; externally peer reviewed.

Open Access This is an Open Access article distributed in accordance with the Creative Commons Attribution Non Commercial (CC BY-NC 3.0) license, which permits others to distribute, remix, adapt, build upon this work non-commercially, and license their derivative works on different terms, provided the original work is properly cited and the use is non-commercial. See: http://creativecommons.org/ licenses/by-nc/3.0/

\section{REFERENCES}

1. Hoes JN, Jacobs JW, Boers M, et al. EULAR evidence-based recommendations on the management of systemic glucocorticoid therapy in rheumatic diseases. Ann Rheum Dis 2007;66:1560-7.

2. Buttgereit $\mathbf{F}$, da Silva JA, Boers M, et al. Standardised nomenclature for glucocorticoid dosages and glucocorticoid treatment regimens: current questions and tentative answers in rheumatology. Ann Rheum Dis 2002;61:718-22

3. Combe B, Landewe R, Lukas C, et al. EULAR recommendations for the management of early arthritis: report of a task force of the European Standing Committee for International Clinical Studies Including Therapeutics (ESCISIT). Ann Rheum Dis 2007;66:34-45

4. Da Silva JA, Jacobs JW, Kirwan JR, et al. Safety of low dose glucocorticoid treatment in rheumatoid arthritis: published evidence and prospective trial data. Ann Rheum Dis 2006;65:285-93.

5. Ezeugo U, Glasser SP. Clinical benefits versus shortcomings of diltiazem once-daily in the chronotherapy of cardiovascular diseases. Expert Opin Pharmacother 2009;10:485-91.

6. Hermida RC, Ayala DE, Fernández JR, et al. Chronotherapy improves blood pressure control and reverts the nondipper pattern in patients with resistant hypertension. Hypertension 2008;51:69-76

7. Smolensky MH, Lemmer B, Reinberg AE. Chronobiology and chronotherapy of allergic rhinitis and bronchial asthma. Adv Drug Deliv Rev 2007;59: 852-82.

8. Straub RH, Cutolo M. Circadian rhythms in rheumatoid arthritis: implications for pathophysiology and therapeutic management. Arthritis Rheum 2007;56: 399-408.

9. Cutolo M, Seriolo B, Craviotto C, et al. Circadian rhythms in RA. Ann Rheum Dis 2003;62:593-6.

10. Cutolo M, Masi AT. Circadian rhythms and arthritis. Rheum Dis Clin North Am 2005;31:115-29.

11. Buttgereit F, Doering G, Schaeffler A, et al. Targeting pathophysiological rhythms: prednisone chronotherapy shows sustained efficacy in rheumatoid arthritis. Ann Rheum Dis 2010;69:1275-80.

12. Kirwan JR, Clarke $L$, Hunt $L P$, et al. Effect of novel therapeutic glucocorticoids on circadian rhythms of hormones and cytokines in rheumatoid arthritis. Ann N Y Acad Sci 2010;1193:127-33.

13. Meyer-Hermann M, Figge MT, Straub RH. Mathematical modeling of the circadian rhythm of key neuroendocrine-immune system players in rheumatoid arthritis: a systems biology approach. Arthritis Rheum 2009;60:2585-94.

14. Straub RH, Paimela L, Peltomaa R, et al. Inadequately low serum levels of steroid hormones in relation to interleukin-6 and tumor necrosis factor in untreated patients with early rheumatoid arthritis and reactive arthritis. Arthritis Rheum 2002;46:654-62.

15. Fries JF, Spitz P, Kraines RG, et al. Measurement of patient outcome in arthritis. Arthritis Rheum 1980;23:137-45.

16. Prevoo ML, van 't Hof MA, Kuper HH, et al. Modified disease activity scores that include twenty-eight-joint counts. Development and validation in a prospective longitudinal study of patients with rheumatoid arthritis. Arthritis Rheum 1995;38: 44-8.

17. Ware JE Jr, Sherbourne CD. The MOS 36-item short-form health survey (SF-36). I. Conceptual framework and item selection. Med Care 1992;30:473-83.

18. Ware JE, Jr., Kosinski M, Keller S. SF-36 Physical and Mental Summary Scales: a user's manual. Boston: The Health Institute, New England Medical Center, 1994.

19. Cella D, Lai JS, Chang $\mathrm{CH}$, et al. Fatigue in cancer patients compared with fatigue in the general United States population. Cancer 2002;94:528-38.

20. Cella D, Yount S, Sorensen M, et al. Validation of the Functional Assessment of Chronic IIIness Therapy Fatigue Scale relative to other instrumentation in patients with rheumatoid arthritis. J Rheumatol 2005;32:811-9. 
21. Felson DT, Anderson JJ, Boers M, et al. American College of Rheumatology. Preliminary definition of improvement in rheumatoid arthritis. Arthritis Rheum 1995; 38:727-35

22. Felson DT, Smolen JS, Wells G, et al. American College of Rheumatology/European League Against Rheumatism provisional definition of remission in rheumatoid arthritis for clinical trials. Arthritis Rheum 2011;63:573-86.

23. Buttgereit F, Doering G, Schaeffler A, et al. Efficacy of modified-release versus standard prednisone to reduce duration of morning stiffness of the joints in rheumatoid arthritis (CAPRA-1): a double-blind, randomised controlled trial. Lancet 2008;371:205-14.

24. Alten R, Döring G, Cutolo $M$, et al. Hypothalamus-pituitary-adrenal axis function in patients with rheumatoid arthritis treated with nighttime-release prednisone. J Rheumatol 2010;37:2025-31.

25. van Everdingen AA, Jacobs JW, Siewertsz Van Reesema DR, et al. Low-dose prednisone therapy for patients with early active rheumatoid arthritis: clinical efficacy, disease-modifying properties, and side effects: a randomized, double-blind, placebocontrolled clinical trial. Ann Intern Med 2002;136:1-12.

26. Capell HA, Madhok R, Hunter JA, et al. Lack of radiological and clinical benefit over two years of low dose prednisolone for rheumatoid arthritis: results of a randomised controlled trial. Ann Rheum Dis 2004;63:797-803.
27. Wassenberg S, Rau R, Steinfeld P, et al. Very low-dose prednisolone in early rheumatoid arthritis retards radiographic progression over two years: a multicenter, double-blind, placebo-controlled trial. Arthritis Rheum 2005;52:3371-80.

28. Kirwan JR. The effect of glucocorticoids on joint destruction in rheumatoid arthritis. The Arthritis and Rheumatism Council Low-Dose Glucocorticoid Study Group. N Engl J Med 1995;333:142-6.

29. Svensson B, Boonen A, Albertsson K, et al. Low-dose prednisolone in addition to the initial disease-modifying antirheumatic drug in patients with early active rheumatoid arthritis reduces joint destruction and increases the remission rate: a two-year randomized trial. Arthritis Rheum 2005;52:3360-70.

30. Todoerti M, Scirè CA, Boffini N, et al. Early disease control by low-dose prednisone comedication may affect the quality of remission in patients with early rheumatoid arthritis. Ann N Y Acad Sci 2010;1193:139-45.

31. Buttgereit F. Szechinski J, Doering G. Integrated summary of safety for modifiedrelease prednisone compared to immediate-release prednisone: Results from the "Circadian administration of prednisone in rhuematoid arthritis". Ann Rheum Dis 2011;70(Suppl 3):88. 